International Journal of Linguistics, Literature and Translation

ISSN: 2617-0299 (Online); ISSN: 2708-0099 (Print)

DOI: 10.32996/ijltt

Journal Homepage: www.al-kindipublisher.com/index.php/ijltt

\title{
A Corpus-Based Study of Gender Difference in the Use of Discourse-Markers among Iranian Translators: A Focus on Functional Appropriateness and DMs which Completely Demonstrate Source Texts Orientation
}

\author{
Bahar Pourshahian 8 (D) \\ Department of General Linguistics, Jahrom University, Jahrom, Iran
}

$\triangle$ Corresponding Author: Bahar Pourshahian, E-mail: bpourshahian@yahoo.com

\section{ARTICLE INFORMATION ABSTRACT}

Received: July 25, 2021

Accepted: August 05, 2021

Volume: 4

Issue: 8

DOI: $10.32996 /$ ijllt.2021.4.8.24

\section{KEYWORDS}

DMs, functional appropriateness, gender, literary translation
Despite the great importance of gender studies and the significance of discourse markers (DMs) in transferring the intention and message, it is not known whether Iranian male translators are aware of the complexities in the meaning of these linguistic elements and whether there is any difference between male /female Iranian translators in the use of discourse markers and the pitfalls while translating literary texts from English to Persian and vice-versa. In addition, the quality of translations of the discourse markers was not assessed yet. Thus, the aim of the present study was to explore the translation of the use of DMs from English to Persian based on Fraser's (2004) and Farahzad (1992) Model. To fulfill the objectives of this study, the researcher selected the data from the original "The Catcher in the Rey" by Salinger using purposive sampling as well as the equivalent two Persian translations by Ahmad Karimi (1345) and Shabnam Eghbalzadeh (1393). After selecting the texts, they were compared with their translations by the researcher and two other raters. The analysis results revealed that there is no significant difference between Karimi (39 cases) and Eghbalzadeh's (40 cases) use of DMs with regard to functional appropriateness. With regard to DMs which completely demonstrate source texts orientation, the frequencies of DMS in Eghbalzadeh's translation is as follows: really (1), before (1), but (11), in the first place (1), in the second place (1), besides (1), when (3), then (2), For one thing (1), for another thing (1), so (3), I mean (3), I guess (2), because (1), at least (1), I don't know (1), I know (2), sort of (0), for instance (1), though (1), well (1), also (0), Because (1), however, the frequencies of DMS in Karimi's translation is: Really (1), before (1), but (12), in the first place (1), in the second place (1), besides (1), when (3), then (2), For one thing (1), for another thing (1), so (3), I mean (3), I guess (2), because (1), at least (1), I don't know (1), I know (2), sort of (0), for instance (1), though (0), well (0), also (1), because (1).

\section{Introduction}

As one type of literary translation, novel translation has always played a significant role in the field of literature. Novel translators have always been faced with translating culturally-bound items of the foreign text into the target system to produce a highly qualified translation (Aixelá, 1996). Novel translators have always been faced with translating culturally-bound items of the foreign text into the target system to produce a highly qualified translation (Aixelá, 1996). However, every translation product has to be assessed. Translated literary texts have been among the genres mostly evaluated in many ways and by various means. However, most of the models used for the assessment of translation quality have been proper for examining either covert or overt translations .

\section{K C AL-KINDI CENTER $\mathbf{R}$ D FOR RESEARCH AND DEVELOPMENT} Your gateway to world-class research

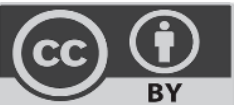

Published by Al-Kindi Center for Research and Development, London, United Kingdom. Copyright (c) the author(s). This open access article is distributed under a Creative Commons Attribution (CC-BY) 4.0 license 
Another obstacle faced by newcomers to the field is the various definitions of the concept of discourse. In a modified version of taxonomy by Bloor and Bloor (2007), it is possible to make the following kinds of distinctions :

1. Discourse is the highest unit of linguistic description; phonemes, morphemes, words, phrases, clauses, sentences and texts are below :

2. Discourse is a sample of language usage, generally written to be spoken, that is, a speech :

3. Discourse refers to the communication expected in one situation context, alongside one field and registers, such as the discourse of law or medicine :

4. Discourse is human interaction through any means, verbal and non-verbal !

5. Discourse is spoken interaction only :

6. Discourse stands for the whole communicative event [original emphasis] (Bloor \& Bloor, 2007, pp. 6-7).

Discourse markers are ubiquitous cohesive devices used to connect what is said or written. However, there is divergence in their usage, placement, and frequency across languages, which is a major problem (Hardmeier, 2012; Meyer \& Popescu-Belis, 2012). Discourse markers can also signal numerous discourse relations and current approaches do not adequately recognize or distinguish between them during the translation process (Hajlaoni \& Popescu-Belis, 2013). Consequently, discourse markers play a significant role in creating and interpreting stretches of speech, because it applies to both spoken and written form of conversation. In a literary work, discourse markers may acquire an even greater significance since the reader has to rely exclusively on the author's choice of formulating and shaping characters' speech. The basic problem they present to translators is that the selection of a target language equivalent is based on the conversational function of the discourse marker. Different languages have established different conventions in using such items and there may be considerable differences in their range, connotation and frequency of usage .

Gender studies and translation studies are the fields of scholarship that occurred at the same time but with unequal development. According to Chamberlain $(1998$, p. 96), "the issues relating to gender in the practice of translation are myriad, varying widely according to the type of text being translated, the language involved, cultural practices and countless other factors".

Malmkjær (1991) states that language studies have two main types in relation to gender. First, it has been observed by many linguists that men and women speak differently. Secondly, it has been observed by many feminists and by some linguists that men and women speak about differently, and it is often claimed that language is discriminatory against women. (p. 345)

However, despite the great importance of literary translations and the significance of discourse markers as well as gender differences in transferring the intention and message, it is not known whether there is any difference between Iranian male/female translators in the use of these linguistic elements and whether they have any pitfalls while translating literary texts from English to Persian and vice-versa. Therefore, the present study made an attempt to answer the following research questions:

1. Is there any difference between Iranian male/female translators in using DMs in terms of functional appropriateness?

2. Is there any difference between Iranian male/female translators in using DMs that completely demonstrate source texts orientation?

\section{Review of the Related Literature}

Wrong use of a DM into a target text (TT) is likely to result in drastic changes in meaning or unintended meanings. Several researchers (McCarthy, 1991; Hamdan \& Fareh, 1999; Saeed \& Fareh, 2006) assert that the accuracy of translated texts should not be superficially evaluated by examining the target language text without corresponding it with the ST text. For instance, McCarthy (1991, pp. 46-47) states that:

Discourse analysts have sought to find out whether the categories and realizations of DMs are similar or different crosslinguistically which is considered an invitation to discourse analysts to conduct contrastive studies that aim at determining the similarities and differences between the various discourse functions of DMs for the sake of displaying the difficulties that translators and foreign language learners encounter.

Dickins, Hervey and Higgins (2002) believe that in case of using an inappropriate DM, translation loss may occur on the prosodic level, for example, since the use of this DM in this particular context shows an informationally inappropriate intonation pattern. This indicates that EFL learners and translators' utmost care and discrimination should be given to the translation of DMs, taking into account the multiplicity of DMs' functions in discourse. 
Karin (2005) provides a very brief discussion of the functions of Arabic DMs, including Oumma. Her discussion of the functions of Oumma is far from being exhaustive. She holds that Oumma has only one discoursal function, a sequential action that comes later than the preceding sentence or clause. In fact, Өumma has more elaborate discoursal functions than the sequential action with a span of time. This succinct review of related studies shed light on the scarcity of cross-linguistic studies on DMs and the need for more in-depth studies that investigate the difficulties that Arab learners of English and translators may encounter in translating from Arabic into English, especially in the area of DMs.

Furko (2014) explored the difficulties translators have to face when translating discourse markers in general and reformulation markers in particular. In the first part of the paper, he attempted to answer the question of why discourse markers are notoriously difficult to translate. Next, he looked at some of the genre-specific features pertaining to the translation of scripted discourse and subtitles. In the second part of the paper, after providing an overview of previous research into reformulation and reformulation markers, he presented the results of a case study of the translation of the English reformulation markers I mean and actually into Hungarian. He finally argued that a wider repertoire of translation strategies is needed to achieve dynamic equivalence in the target text.

In the same vein, Kafipour (2016) aims to research and investigate errors in the translation of discourse markers (DMs) from English into Persian in the subtitles of drama movies. To fulfil the objectives of this study, he chose five movies, including Taxi Driver (1973) written by Paul Schrader, raging bull (1980) written by Paul Schrader, Shawshank Redemption (1994) written by Frank Darrabont, The Departed (2006) written by William Monnahan and Bad Teacher (2011) written by Lee Eisenburg and Gene Stupnitsky. After selecting the movies, six commonly used DMs namely you know, you see, look, oh, I mean, and now. Were searched and obtained by the aid of computer softwares (AntConc and adobe acrobat reader ${ }^{\mathrm{TM}}$ ). These DMs were categorized based on their functions in the original work. The obtained DMs in this study were analyzed carefully by the researcher and errors in translation were identified and categorized according to Chaume (2004) model. The results and chi-square showed that omission is the most prevailing error made by Iranian translators in translating English subtitles into Persian followed by literal translation and translation to another DM.

\section{The Present Study}

The data of the present quantitative study were derived from every other chapter of the original "The Catcher in the Rey" by Salinger, along with Persian translations by Karimi (1345) and Eghbalzadeh (1393) using purposive sampling. The reason to select this book for the case study was threefold: its popularity worldwide, having many translations in Persian and the researcher's self-interest in the book. The two translations by Ahmad Karimi and Eghbalzadeh were selected because of the translators' experience and various works translated.

To fulfill the objectives of this study the following steps were taken:

1. At first, the data of the study were derived from the original "The Catcher in the Rey" by Salinger and two Persian translations by Eghbalzadeh and Karimi.

2. Second, the discourse markers of the original texts were identified and classified according to Fraser's (2004) model;

3. Then they were introduced to the evaluators of the translated texts, by the researcher.

4. Next, their occurrences in the original texts were compared to their translations.

5. Finally, the translated texts were evaluated by the two experienced T.S teachers as well as the researcher for their reliability according to Farahzad's (1992) scale.

In order to analyze the selected data, the researcher used the frequency of the statistical procedure.

\section{Results and Discussion}

In the tables listed below, samples from ST were compared with that of TT by Karimi's (1345) and Eghbalzadeh's translation (1393). It should be worth noting that the first raw translation belongs to Karimi and the second raw to Eghbalzadeh (1393). Farahzad's (1992) TQA criteria, namely, functional appropriateness was of concern in the analysis below. 
A: Findings Concerning Functional Appropriateness in English to Persian Translation of "The Catcher in the Rey" by Karimi's (1345) and Eghbalzadeh (1393) based on Farahzad's (1992)

\section{Sample 1}

\begin{tabular}{|c|c|c|}
\hline ST & TT & Functional Appropriateness \\
\hline \multirow[t]{2}{*}{$\begin{array}{l}\text { If you really want to hear about } \\
\text { it, the first thing you'll probably } \\
\text { want to know is where I was } \\
\text { born, }\end{array}$} & 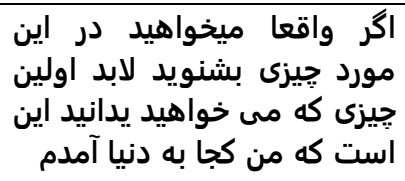 & functionally appropriate \\
\hline & 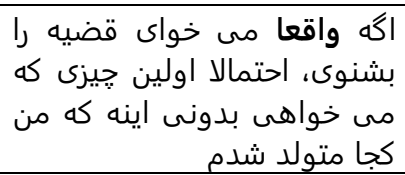 & functionally appropriate \\
\hline
\end{tabular}

\section{Sample 2}

\begin{tabular}{|c|c|c|}
\hline ST & TT & Functional Appropriateness \\
\hline \multirow[t]{2}{*}{ and all before they had me } & 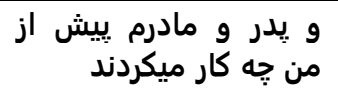 & Functionally appropriate \\
\hline & 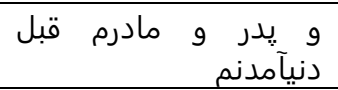 & Functionally appropriate \\
\hline
\end{tabular}

\section{Sample 3}

\begin{tabular}{|l|r|l|}
\hline \multicolumn{1}{|c|}{ ST } & TT & \multicolumn{1}{|c|}{ Functional Appropriateness } \\
\hline \multirow{2}{*}{$\begin{array}{l}\text { I think she was glad to see } \\
\text { me. }\end{array}$} & functionally inappropriate \\
\cline { 2 - 3 } & functionally appropriate \\
\hline
\end{tabular}

\section{Sample 4}

He's going to drive me home when I go home next month maybe functionally inappropriate

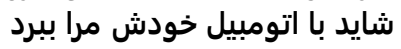

functionally inappropriate با ماشينش منو برسونه

\section{Sample 5}

but you could hear them all Pencey side, yelling, deep and terrific on the

\begin{tabular}{|c|c|}
\hline 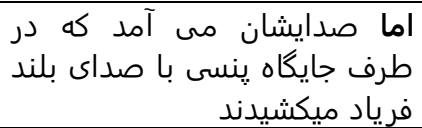 & functionally appropriate \\
\hline 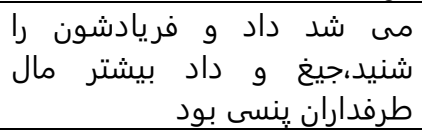 & functionally inappropriate \\
\hline
\end{tabular}

According to the descriptive results of this analysis which are shown above and based on the total frequency of functionally appropriate DMs regarding Farahzad's (1992) Model, there is no significant difference between Karimi (39 cases) and Eghbalzadeh's translation (40 cases) with regard to functional appropriateness 
Table1. A Comparison of Functional Appropriateness between Karimi and Eghbalzadeh's Translation based on Farahzad's (1992) model

\begin{tabular}{|l|c|}
\hline \multicolumn{2}{|c|}{ Functional Appropriateness in terms of frequency } \\
\hline Karimi & $\mathbf{3 9}$ \\
\hline Eghbalzadeh & $\mathbf{4 0}$ \\
\hline
\end{tabular}

B: Findings Concerning Frequency of DMs which Completely Demonstrate Source Texts Orientation in English to Persian Translation of "The Catcher in the Rey" by Karimi's (1345) and Eghbalzadeh (1393)

Table2. DMs which Completely Demonstrate Source Texts Orientation

\begin{tabular}{|c|c|c|c|c|}
\hline \multirow{2}{*}{$\begin{array}{l}\text { DMs which completely } \\
\text { demonstrate source texts } \\
\text { orientation }\end{array}$} & \multicolumn{2}{|c|}{ Frequency (N) } & \multicolumn{2}{|c|}{ Percentage (\%) } \\
\hline & Karimi & Eghbalzadeh & Karimi & Eghbalzadeh \\
\hline Really & 1 & 1 & 2.5 & 2.5 \\
\hline Before & 1 & 1 & 2.5 & 2.5 \\
\hline But & 11 & 11 & 27.5 & 27.5 \\
\hline In the first place & 1 & 1 & 2.5 & 2.5 \\
\hline In the second place & 1 & 1 & 2.5 & 2.5 \\
\hline Besides & 1 & 1 & 2.5 & 2.5 \\
\hline When & 3 & 3 & 7.5 & 7.5 \\
\hline Then & 2 & 2 & 5 & 5 \\
\hline For one thing & 1 & 1 & 2.5 & 2.5 \\
\hline For another thing & 1 & 1 & 1 & 1 \\
\hline So & 3 & 3 & 7.5 & 7.5 \\
\hline I mean & 3 & 3 & 7.5 & 7.5 \\
\hline I guess & 2 & 2 & 5 & 5 \\
\hline Because & 1 & 1 & 2.5 & 2.5 \\
\hline At least & 1 & 1 & 2.5 & 2.5 \\
\hline I don't know & 1 & 1 & 2.5 & 2.5 \\
\hline I know & 2 & 2 & 5 & 5 \\
\hline Sort of & 0 & 0 & 0 & 0 \\
\hline For instance & 1 & 1 & 2.5 & 2.5 \\
\hline Though & 0 & 1 & 0 & 2.5 \\
\hline Well & 0 & 1 & 0 & 2.5 \\
\hline also & 1 & 0 & 2.5 & 0 \\
\hline Total & 39 & 40 & 100 & 100 \\
\hline
\end{tabular}

The frequencies of DMS in Eghbalzadeh's translation is as follows: really (1), before (1), but (11), in the first place (1), in the second place (1), besides (1), when (3), then (2), For one thing (1), for another thing (1), so (3), I mean (3), I guess (2), because (1), at least (1), I don't know (1), I know (2), sort of (0), for instance (1), though (1), well (1), also (0), Because (1), however, the frequencies of DMS in Karimi's translation is: Really (1), before (1), but (11), in the first place (1), in the second place (1), besides (1), when (3), then (2), For one thing (1), for another thing (1), so (3), I mean (3), I guess (2), because (1), at least (1), I don't know (1), I know (2), sort of (0), for instance (1), though (0), well (0), also (1), because (1).

The findings of this study are in line with Furko (2014) in that both studies argued that a wider repertoire of translation strategies is needed in order to achieve dynamic equivalence in the target text. 


\section{Conclusion}

It is accepted that translating DMs is difficult. The main reason for such difficulty in their translation is their multi-functionality and "the fact that they do not translate very well directly, i.e. "[DMs] do not translate well in the sense that they have no satisfying correspondences in other languages" (Aijmer, 2008, p. 95). Due to the non-transparency of DMs, translating them is never a straightforward task. Nida's (1964) formal and dynamic equivalence must be brought up in relation to DM translation, particularly in relation to the subtitling of DMs. In brief, formal equivalence can be defined as "focus[ing] attention on the message itself, in both form and content" (Nida, 1964, p.159), i.e. a more literal translation, whereas dynamic equivalence is based upon "the principle of equivalent effect" (Nida, 1964, p.159.), i.e. a more free translation. Mattson (2009) believes that reaching dynamic equivalence between ST and subtitle is more feasible and possibly results in a more accessible translation. Gottlieb (1997) and Chaume (2004) are both inspired by Nida's (1964) terminology because they conclude that the most important task of translation is to "produce a similar effect on the target language audience as the source text produced on the source culture audience" (Chaume, 2004, p.844).

Aijmer and Vandenbergen (2003) believe that due to DMs' multi-functionality, producing the same effect that DMs had on the audience of the source language on the audience of the target language is very complicated difficult.

Regarding the growing interest in getting acquainted with other cultures and attitudes through reading literary texts and their translations, the need for translation enhances in a world wrapped up in various beliefs and attitudes. The translators produce the target texts to provide those who do not know the foreign language with what they desire. Among the very translations produced, there may be some that might not be transferred with great care, and they may cause misunderstandings. Translation quality assessment (TQA) is one way to evaluate the existing translations to differentiate good translations from those not translated with great care. The result can helpfully guide people to choose an adequate translation.

As one type of literary translation, novel translation has always played a significant role in the field of literature. Novel translators have always been faced with translating culturally-bound items of the foreign text into the target system to produce a highly qualified translation. However, every translation product has to be evaluated. Translated literary texts have been among the genres mostly evaluated in many ways and by various means.

\section{References}

[1] Aixela, J. (1996). Culture-specific items in translation. Clevedon- Philadelphia-Adelaide: Multilingual Matters

[2] Aijmer, K and Simon-Vandenberg, A.M. (2003). The discourse particle well and its equivalents in Swedish and Dutch. Linguistics, 41(6), pp. 1123-1161.

[3] Bloor, M. and Bloor, T. (2007). The Practice of Critical Discourse Analysis. London: Hodde Education.

[4] Chamberlain, L. (1998). Gender Metaphorics in Translation. In M. backer (Ed.) Encyclopedia of Translation Studies (pp. 93-96). London: Routledge.

[5] Chaume, F. (2004). Discourse Markers in audiovisual translating. Translators' Journal 94(4), pp. 843-855.

[6] Dickins, J., Hervey, S. and Higgins, I. (2002). Thinking Arabic translation: a course in translation method: Arabic into English. London: Routledge

[7] Eghbalzadeh. S. (2013). باطور ششت Publication

[8] Farahzad, F. (1992). Testing Achievement in Translation Classes. In C. Dollerup and A. Loddegaard (Eds) Teaching Translation and interpreting. Training, Talent and Experience. Papers from the First Language International Conference. Amsterdam and Philadelphia: John Benjamins, pp. 271-8.

[9] Fraser, B. (2004). An account of discourse markers. In Garces P.R. Gomez, L. Fernandez, M. Padilla. (Eds). Current trends in intercultural cognitive and social pragmatics. Seville: Universidad desevilla: 13-34.

[10] Gottlieb, H. (1997). Quality revisited. In A. Trosborg (Ed.), Text Typology and Translation. Amsterdam, Philadelphia: John Benjamins.

[11] Hajlaoui, N; Popescu-Belis, A. (2013). Translating English Discourse Connectives into Arabic: A Corpus-based analysis and an Evaluation Metric. In: CAASL4 Workshop at AMTA (Fourth Workshop on Computational Approaches to Arabic Script-based Languages), San Diego, CA.

[12] Hamdan, J. and Fareh, S. (1999). The translation of Arabic WA into English: Some problems and implications. Dirasat: Human and Social Sciences 26, 2. 590-603.

[13] Hardmeier, Ch., (2012). Discourse in Statistical Machine Translation: A Survey and a Case Study Elanders Sverige, Sweden.

[14] Karimi, A. (1345). ناطور شت Mina Publication

[15] Karin C.R. (2005). A Reference grammar of modern standard Arabic. Cambridge University Press.UK.

[16] Malmkjær, K (Ed.). (1991). The linguistics encyclopedia. London and New York: Routledge.

[17] Mattson, J. (2009). The subtitling of discourse particles - A corpus-based study of well, you know, I mean, and like, and their Swedish translations in ten American films. Ph.D. University of Gothenburg

[18] McCarthy, M. (1991). Discourse analysis for language teachers. Cambridge: Cambridge University Press

[19] Meyer, T; Popescu-Belis, A. (2012). Using sense-labeled discourse connectives for statistical machine translation. In: EACL Joint Workshop on Exploiting Synergies between IR and MT, and Hybrid Approaches to MT (ESIRMTHyTra), pages 129-138. Avignon, France

[20] Nida, E.A. (1964). Towards a science of translating. Leiden: E.J. Brill. 
[21] Saeed A.T. \& Fareh, S (2006). Difficulties encountered by bilingual Arab learners in translating Arabic FA into English. The International Journal of Bilingual Education and Bilingualism, Vol. 9, No.1.19-31.

[22] Salinger, J.D. (1945). The Catcher in the Rey. New York. Little, Brown and Company. 